\title{
THE CONCEPT OF 'ROADMAPPING SERVICE': EXPLORING CUSTOMER PERSPECTIVES OF ROADMAPPING THROUGH THE SERVICE LENS
}

\author{
Oliveira, Maicon Gouvea (1); Routley, Michele (2); Phaal, Robert (2); Mendes, Glauco Henrique \\ Sousa (3) \\ 1: Federal University of Alfenas; 2: University of Cambridge; 3: Federal University of Sao Carlos
}

\begin{abstract}
Roadmapping has been addressed as a management approach used to support strategic and innovation planning of organisations over recent decades. This paper introduces a new standpoint for addressing roadmapping through the application of service theories as a way for tackling the demand for the digitalisation of roadmapping. To this end, the concept of roadmapping as a service offer is developed and employed to analyse three customer perspectives of roadmapping: owners and sponsors, team members, and facilitators. Based on a literature review and interviews with roadmapping experts, customer jobs, pains, and gains are described for each of the perspectives. In the end, the paper provides insights for the understanding of the concept of roadmapping service and opens opportunities for further theoretical and empirical developments around this new path. These results are part of a broader research project exploring the digitalisation of roadmapping.
\end{abstract}

Keywords: Roadmapping, Service design, Innovation, Digitalisation, Design methods

\author{
Contact: \\ Oliveira, Maicon Gouvea \\ University of Cambridge \\ Institute for Manufacturing \\ United Kingdom \\ maicongdo@outlook.com
}

Cite this article: Oliveira, M.G., Routley, M., Phaal, R., Mendes, G.H.S. (2019) 'The Concept of 'Roadmapping Service': Exploring Customer Perspectives of Roadmapping through the Service Lens', in Proceedings of the 22nd International Conference on Engineering Design (ICED19), Delft, The Netherlands, 5-8 August 2019. DOI:10.1017/ dsi.2019.317 


\section{INTRODUCTION}

The development of strategic and planning tools in the technology and innovation management field has grown considerably in recent years (Whitney, 2007; Vuorinen et al., 2018; Phaal et al., 2006a, 2006b). Similarly, roadmapping has increased in terms of employed processes and best practices (Carvalho et al., Lopes, 2013; Vatananan and Gerdsri, 2012; Gerdsri et al., 2013). Roadmapping has mainly been built upon practices that rely on visualization techniques and human collaboration (interaction and communication) to enhance performance and achieve more effective results for strategic and tactical planning (Phaal et al., 2004, 2010; Kerr et al., 2012a). However, the digitalization of organizational processes has stimulated the introduction of digital technologies into roadmapping (Schimpf and Abele, 2017).

Despite the discussion of the digitalisation concept in academia and industry, it is not simple to find a general definition due to its broad coverage; spanning from specific technologies to new business models (Hess et al., 2016; Lanzolla and Anderson, 2008; McAfee and Brynjolfsson, 2017). Bloomberg (2018) provides a relevant explanation for three interdependent parts in this context: digitisation, digitalisation and digital transformation. For this study, digitalisation is defined as the introduction of digital technologies into existing business practices for improving processes, roles and decisions. Therefore, the digitalisation of roadmapping refers to the introduction of digital technologies into existing roadmapping practices.

The step towards digitalisation in roadmapping should be carefully assessed and understood before being undertaken. Otherwise, it may hinder critical advantages related to face-to-face interactions and agile activities based on simple and visual artefacts like sticky notes and fast-start workshops. In fact, the safeguards related to the digitalisation of roadmapping can be a key matter of concern for some roadmapping stakeholders.

At this point, this study recognised an opportunity to look at roadmapping using service theories. This approach could allow for the development of a new perspective capable of supporting an effective way for addressing the digitalisation of roadmapping. Following this research opportunity, this study adopts that roadmapping can be seen as a service which is provided to customers. Thus, the service value offered through roadmapping can be analysed to support customers interested in the potential benefits provided by digitalisation.

Although roadmapping has been extensively studied and there is much knowledge available in the literature (Carvalho et al., Lopes, 2013; Vatananan and Gerdsri, 2012; Gerdsri et al., 2013), little is known, from a research perspective, about the customer perspectives of roadmapping. Moreover, the investigation of customer perspectives can be a first step towards the transition to a digitalised value offer of roadmapping following the service lens (Vargo and Lusch, 2004).

In this context, this paper aims to explore the customer perspectives of roadmapping. This can provide understanding about the contribution of roadmapping to organizations and people and, as a result, support the understanding of how digitalisation could be correctly addressed to create value to the roadmapping service offer.

To this end, first a literature review was conducted to identify the main types of roadmapping customers and to collect examples of their needs. Then, using the customer profile model proposed by Osterwalder et al. (2014), experts were interviewed to collect their views concerning jobs, pains, and gains related to roadmapping. Afterwards, data was reviewed, analysed and clustered to form an initial view of the customer perspectives of roadmapping.

\section{ROADMAPPING AS A SERVICE OFFER}

Roadmapping has evolved to be much more than a method for supporting technology and product planning. Originally, it was applied by organizations such as Motorola (Willyard and McClees, 1987) and Sandia (Bray and Garcia, 1997) to support the foreseeing and planning of technological and product changes required to follow market and business requirements. At this time roadmapping was mainly referred to as 'Technology Roadmapping' (TRM), reinforcing its technical perspective. Moreover, it was mostly addressed as an industrial practice and, thus, it was little understood from an academic perspective (Phaal et al., 2010).

From the mid-1990s, there were several attempts to research roadmapping and its potential contribution as an approach for the technology and innovation management field. Among these are the T-Plan guide (Phaal et al., 2001) by the Institute for Manufacturing of the University of Cambridge; 
the MATI consortium (Radnor and Peterson, 1999) in the United States; and EIRMA in Europe (EIRMA, 1997). The Research Technology Management Journal's special issue in 2004, is also noteworthy, presenting several roadmapping cases and research topics.

From 2010 until now, roadmapping seems to have moved to a much more comprehensive strategic approach. In fact, this strategic approach was first noticed by Phaal et al. (2007). Then, roadmapping started to be commonly described as 'Strategic Roadmapping' or just 'Roadmapping'. Moreover, it has assumed a broader scope, extending its unit of analysis from products, technologies, and platforms to business units, corporations, and sectors (Phaal et al., 2010). Consequently, the requirements of roadmapping applications also changed to satisfy requirements related to, for example, strategy formulation, prioritisation, scenario analysis, and risk management. Although product-technology roadmapping applications are still relevant and conducted in industry, they seem to be less of a focus for research studies in recent years.

One relevant characteristic of roadmapping that can be stated as one of the differentiators for the industrial adoption is the use of a new style of working principles (Kerr et al., 2012a). Although not very clear in the first applications (Bray and Garcia, 1997; Willyard and McClees, 1987), the working principles surrounding the development of roadmapping have been always based on simple, visual, and workshop-based practices, referred to as a 'fast-start approach' (Phaal et al., 2003, 2004). These principles are influenced by the lean manufacturing principles (Liker, 2004) and by the early design thinking approaches disseminated by IDEO (Brown, 2009) and they are also aligned with the more contemporary agile management principles (Conforto et al., 2016) seen in the business model canvas (Osterwalder and Pigneur, 2010).

Due to such influences, roadmapping has become more a framework of practices, guiding industrial activities related to technological and innovation planning, rather than a specific method or process. Adding a new insight from a service-dominant logic (Vargo and Lusch, 2004), roadmapping can be also seen as a service, since it encompasses knowledge and capabilities used by organizations to develop their business processes.

Hill (1977, p.318) defines service as “... as a change in the condition of a person, or of a good, belonging to some economic unit, which is brought about as the result of the activity of some other economic unit, with the prior agreement of the former person or economic unit." Thus, roadmapping can be framed within this definition as the service used to change the condition of business processes (good) of organisations (economic unit) by means of an activity conducted by internal or external facilitators (other economic unit) hired by organisations (prior agreement). This understanding of roadmapping as a service is also aligned with Vargo and Lusch $(2004$, p.2), who defines service as "... the application of specialized competences (knowledge and skills) through deeds, processes, and performances for the benefit of another entity or the entity itself".

The application of the service paradigm is also found in other management activities. For example, project management is already dealt with by PMOs (project management offices), which are an outsourcing service of project management activities, initially provided by operations managers (product, technology, etc) to new internal departments or even to external service providers (Hill, 2004).

Considering roadmapping as a service rather than only a management process also raises the opportunity of analysing it through a capability perspective. Capabilities can be defined as "the ability or power to do something" (McIntosh, 2013). Thus, companies that aim to exploit roadmapping have either to develop roadmapping capabilities internally or acquire it from external service providers such as consultancies.

Once roadmapping is recognized as a service underpinned by organizational capabilities, it can be analysed and designed through new lenses. A first proposal in this sense, adopted in this study, is addressing customer perspectives of the roadmapping value proposition. This proposal is explained in the next section.

\section{CUSTOMER PERSPECTIVES OF ROADMAPPING}

Christensen et al. (2007) described the concept of jobs. According to the authors, companies miss the correct understanding of customer behaviour or needs by setting market segments when trying to plan and improve product or service offers. In contrast, they state that companies need to understand and 
exploit jobs that customers are trying to solve with products and services they consume. They propose that "a job is the fundamental problem a customer needs to resolve in a given situation".

Bettencourt et al. (2014) add the service lens perspective to promote value creation to customers. They introduce the service lens as capable of guiding companies to find the correct proposal to support customers in their jobs. In the same vein, Osterwalder et al. (2014) posit the understanding of customer jobs, pains, and gains in the value proposition design. In fact, value propositions are independent of the media used for delivering value to customers (for example - goods or services). Thus, the value proposition design should focus on finding the best solution - ranging from physical products, through mixed product-service offers or service-based solutions (Tukker, 2004) - to satisfy customer jobs based on the company's capabilities. Osterwalder et al. (2014) provide the following definitions of jobs, pains and gains:

- Jobs: "Things customers are trying to get done in their work ... tasks to complete, problems to solve, needs to satisfy." Osterwalder et al. $(2014, p .12)$

- Pains: "Anything that annoys your customers before, during, and after trying to get a job done or simply prevents them get it done." Osterwalder et al. $(2014, p .14)$

- Gains: "Describe the outcomes and benefits your customers want. They include functional utility, social gains, positive emotions, and cost savings. "Osterwalder et al. $(2014$, p.16)

Based on this, the understanding of roadmapping customers' jobs, pains and gains is the first step for developing a new value proposition for roadmapping. Since different customer perspectives (segments) may exist for the same solution, this study started by exploring the most relevant customer perspectives of roadmapping. Thus, based on a literature review (Oliveira et al., 2012; Phaal et al., 2010, 2015), three customer perspectives were identified, as described in Figure 1:

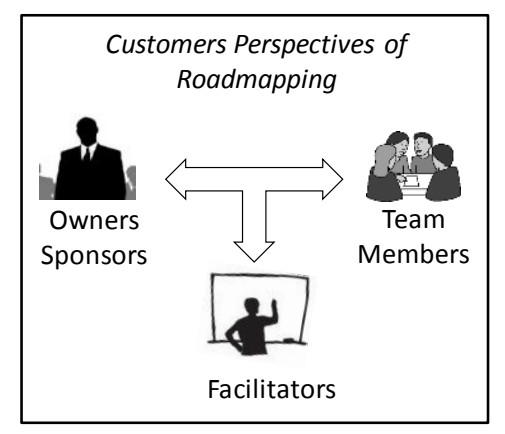

Figure 1. Customer perspectives of roadmapping

- $\quad$ Roadmapping Owners and Sponsors: owners are usually assigned to the business process for which roadmapping is intended to create value. For example, product managers, technology managers, business managers, etc. They tend to have a clear understanding about the results they want to achieve using roadmapping and they often support the definition of roadmapping goals and resource allocation. Sponsors have similar expectations to owners, but they are more interested in the outcomes of roadmapping and, hence, tend to have minor involvement in its execution. Nevertheless, from an organizational perspective, they can be as relevant to roadmapping success.

- Roadmapping Team Members: they are the people involved in the activities to develop the roadmaps and usually contribute by bringing and sharing information, building plans, making decisions, etc. Team members can be from the department that is sponsoring the roadmapping development or from any other part of the organization. Furthermore, they can also be external participants, who are invited to complement information and provide an external and impartial viewpoint. Since they actively participate in the roadmapping activities, they have the opportunity to influence results achieved and decisions. In this sense, team members differ from owners and sponsors as they can directly affect the value creation process.

- $\quad$ Roadmapping Facilitators: they are the people who are expected to have capabilities in roadmapping development and, thus, support the design of the roadmapping approach with owners and sponsors, and the execution of roadmapping activities with team members. Facilitators can be consultants or members of the organization. The critical point is that they should be impartial and have enough experience to use the roadmapping working principles and flexibility to meet the objectives.

The next section describes the research method followed in this study. 


\section{RESEARCH METHOD}

This study intends to build theories for the technology and innovation management field. Theory building research aims to develop understanding of existing phenomena and create knowledge capable of solving issues hindering the progress of academia, practice and society (Karlsson, 2016). According to Karlsson (2016), there are three different logics of research: deduction, induction and abduction. This study follows the abduction logic through the application of the Design Research Methodology (DRM) (Blessing and Chakrabarti, 2009) to investigate and develop new concepts and knowledge for the roadmapping research domain. Following the DRM framework, two of its stages are within the scope of this paper: Research clarification and Descriptive studies.

The research clarification stage considers the identification of evidence that supports the establishment of research goals (Blessing and Chakrabarti, 2009). A summary of the results of this stage were explained in the 'introduction' and 'roadmapping as a service' sections.

The second stage, descriptive studies, aims to acquire information about the phenomenon of study through the review of literature and, if required, through empirical observation and data collection (Blessing and Chakrabarti, 2009). For this stage, first a literature review was conducted to identify and describe the customer perspectives of roadmapping (previous section). Then, to explore in-depth each perspective, empirical data were collected through one-hour interviews with five experts in roadmapping. Two are academics with more the than 10 years of experience in roadmapping research and consultancy. The other three are consultants. One with more than 10 years of experience in roadmapping and the other two with more than 5 years of experience. All of them are classified as experts in the field of roadmapping based on an analysis of their knowledge and past working examples.

Although it is important to consider the customer perspectives separately, the first step of this research focused on developing an overview for the three perspectives. Therefore, at this moment, experts with a broad view of roadmapping were involved.

The data collection in the interviews and the analysis of the customer perspectives followed the customer profile model proposed in Osterwalder et al. (2014). This model was selected due to the alignment with the concepts of jobs and value creation and because it has been extensively adopted and validated.

The interviews with the experts were conducted individually. First, the interviewees were introduced to the proposed concepts of roadmapping customers and to the definitions of jobs, pains and gains. Then some examples were given using the visual layout of the value proposition model to support the brainstorming of ideas for each of the customer types and the results collected using sticky notes, as depicted in Figure 2. The examples, partially shown in Table 1, were defined based on a literature review (Cosner et al., 2007; Gerdsri et al., 2009, 2010; Groenveld, 1997; Grossman, 2004; Kappel, 2001; Kerr et al., 2012a, 2012b; Kerr and Phaal, 2015; Kostoff and Schaller, 2001; Oliveira et al., 2012; Phaal et al., 2010) and on the experience of one of the authors, who has been working with roadmapping for research and consultancy since 2008. Table 1 also show the total number of jobs, pains and gains acquired as examples for using in the interviews.

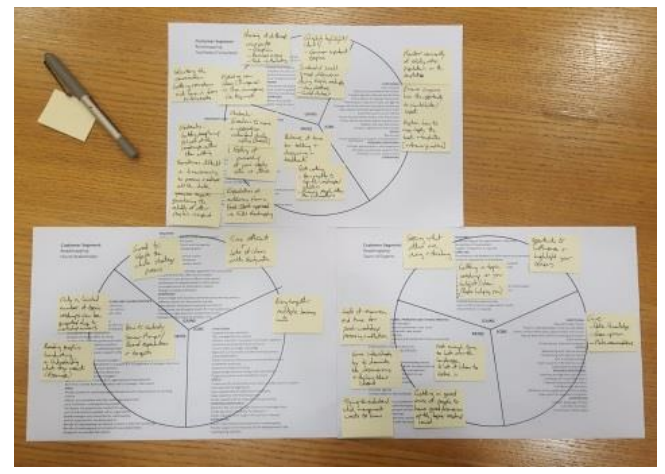

Figure 2. Collection of experts' data for the customer perspectives of roadmapping using examples in the value proposition framework and sticky notes 
Table 1. Examples of jobs, pains and gains used for guiding interviews

\begin{tabular}{|l|l|}
\hline \multicolumn{1}{|c|}{ Perspective } & \multicolumn{1}{c|}{ Indicative Literature Examples } \\
\hline $\begin{array}{l}\text { Owner/Sponsors } \\
\text { Jobs - 22 examples }\end{array}$ & $\begin{array}{l}\text { Support business decisions; Plan strategic/tactical actions; Define a vision for } \\
\text { a business or innovation platform; Forecast and analyse future scenarios; etc. }\end{array}$ \\
\hline $\begin{array}{l}\text { Owner/Sponsors } \\
\text { Pains - 30 examples }\end{array}$ & $\begin{array}{l}\text { Lack of vision for the future; Constant changes in business directions; People } \\
\text { not committed with the roadmapping activities; Lack of resources for } \\
\text { involving experts; etc. }\end{array}$ \\
\hline $\begin{array}{l}\text { Owner/Sponsors } \\
\text { Gains - 19 examples }\end{array}$ & $\begin{array}{l}\text { Share and align information; Change in people motivation; Reshape of } \\
\text { organizational strategic view; Prioritize most important points; etc. }\end{array}$ \\
\hline $\begin{array}{l}\text { Facilitators } \\
\text { Jobs - 20 examples }\end{array}$ & $\begin{array}{l}\text { Prepare agenda, materials and facilities; Networking; Develop new business } \\
\text { opportunities; Manage individual and team working in workshops; Ensure } \\
\text { democratic participation and decisions; etc. }\end{array}$ \\
\hline $\begin{array}{l}\text { Facilitators } \\
\text { Pains - 16 examples }\end{array}$ & $\begin{array}{l}\text { Results no aligned with goals; Lack of alignment of people schedule; Much } \\
\text { time to consolidate information; Lack of appropriate resources and facilities; } \\
\text { Few people dominating the speech; etc. }\end{array}$ \\
\hline $\begin{array}{l}\text { Facilitators } \\
\text { Gains - 24 examples }\end{array}$ & $\begin{array}{l}\text { Sense of alignment and priorities among people involved; Results ready to } \\
\text { share; Complete execution of the agenda; Achievement of the goals; etc. }\end{array}$ \\
\hline $\begin{array}{l}\text { Team Members } \\
\text { Jobs - 17 examples }\end{array}$ & $\begin{array}{l}\text { Brainstorming; Team working; Learning new knowledge topics; Influence on } \\
\text { the organizational future paths; etc. }\end{array}$ \\
\hline $\begin{array}{l}\text { Team Members } \\
\text { Pains - 17 examples }\end{array}$ & $\begin{array}{l}\text { Stressful discussions; Lack of interest in the subject; Discussion of sensitive } \\
\text { information; No feedback on the results achieved; etc. }\end{array}$ \\
\hline $\begin{array}{l}\text { Team Members } \\
\text { Gains - 17 examples }\end{array}$ & $\begin{array}{l}\text { Recognition of involvement; Access to organization's information; Active } \\
\text { and motivating workshops; Job promotion or rewards; etc. }\end{array}$ \\
\hline
\end{tabular}

Since the initial examples used to conduct interviews were extensive, the interviewees mainly contributed with structuring, organising and clarifying the existing items. Once input from the experts was collected, it was organised and grouped to deliver a unified view regarding jobs, pains and gains for each one of the three customer perspectives. The same approach using sticky notes for organisation and analysis of data was followed in this study to reach this single view, which is presented in the next section.

\section{RESULTS}

The results achieved for the customer perspectives of roadmapping are shown in Table 2.

Table 2. Customer perspectives of roadmapping analysed and refined after interviews

\begin{tabular}{|l|l|l|}
\hline \multicolumn{2}{|c|}{ Perspective } & \multicolumn{1}{c|}{ List } \\
\hline Sponsors & Jobs & $\begin{array}{l}\text { Improvement of Business Performance; Making Investment Decisions; } \\
\text { Generation of Ideas; Communication of Business Aims; } \\
\text { Communication of Business Aims; Management of Risks and } \\
\text { Uncertainties; Creation and Alignment of Strategic Vision }\end{array}$ \\
\cline { 2 - 3 } & Pains & $\begin{array}{l}\text { Lack of Resources for Roadmapping; Inefficient Roadmapping Process; } \\
\text { Ineffective Roadmapping Process; Organisational Resistance to } \\
\text { Change/Novelty; Organisational Resistance to Change/Novelty; Lack } \\
\text { of Availability of Information; Difficulty of Managing Different } \\
\text { Stakeholders' Expectations; Difficulty of Involving External People; } \\
\text { Difficulty of Defining the Scope of Analysis; Difficulty of Protecting } \\
\text { Sensitive Information }\end{array}$ \\
\cline { 2 - 3 } & Gains & $\begin{array}{l}\text { Support for the Sharing of Expert Knowledge; Diagnosis of Critical } \\
\text { Business Issues; Improvement of Organisational Alignment; Accessing } \\
\text { Different Points of View; Application of Agile Process and Practices; } \\
\text { Discovery of New Opportunities; Support for Participants Reaching } \\
\text { Agreements; Making Decisions with More Confidence }\end{array}$ \\
\hline
\end{tabular}




\begin{tabular}{|l|l|l|}
\hline $\begin{array}{l}\text { Team } \\
\text { Members }\end{array}$ & Jobs & $\begin{array}{l}\text { Giving Opinions and Suggestions; Networking with Other Team } \\
\text { Members; Search for Data and Information; Sharing and Acquisition of } \\
\text { Knowledge and Insights; Contribution with Group Working }\end{array}$ \\
\cline { 2 - 3 } & Pains & $\begin{array}{l}\text { Lack of Support from Business Area to Participate; Lack of } \\
\text { Understanding about the Roadmapping Process and Results; Lack of } \\
\text { Expertise in the Scope of Analysis; Fear of Being Misjudged by Others; } \\
\text { Difficulty of Contributing with Group Work; Fear of Sharing Ideas }\end{array}$ \\
\cline { 2 - 4 } Facilitators & $\begin{array}{l}\text { Improved Personal Knowledge; Opportunity to Innovate the Own Job; } \\
\text { Better Understanding of Business Decisions; Opportunity to Do } \\
\text { Personal Marketing; Better Understanding of Others' Thoughts and } \\
\text { Wishes; Opportunity to Influence on Business Decisions }\end{array}$ \\
\cline { 2 - 4 } & $\begin{array}{l}\text { Preparation of Workshops and Materials; Acquisition of Knowledge; } \\
\text { Promotion of a Creative and Learning-Oriented Environment; } \\
\text { Management and Sharing of Data and Information; Networking with } \\
\text { Participants; Explanation of the Roadmapping Process and Tools; Time } \\
\text { Management; Delivering Value to Customers; Promotion of Fair Group } \\
\text { Working; Design and Management of the Roadmapping Process }\end{array}$ \\
\hline $\begin{array}{l}\text { Presence of Participants Misleading or Stopping Others' Contribution; } \\
\text { Difficulty of Following the Designed Roadmapping Process; Difficulty } \\
\text { of Reacting to Realtime Changes and New Demands; Difficulty of } \\
\text { Making Prioritisation Decisions; Difficult and Time-consuming Data } \\
\text { Processing; Difficult and Time-consuming Data Processing; Difficult } \\
\text { and Time-consuming Data Processing; Workload Uncertainty; Limited } \\
\text { Participation and Interaction; Misaligned Expectations about the } \\
\text { Roadmapping Results }\end{array}$ \\
\hline $\begin{array}{l}\text { Best-in-class Roadmapping Performance and Results; Constructive } \\
\text { Feedback for Improving the Roadmapping Process; Positive Feedback } \\
\text { about Group Working; Presence of Rich and Multidisciplinary Debates; } \\
\text { Roadmapping Results Agreed Among Participants }\end{array}$ \\
\hline Gains
\end{tabular}

In Table 2, it can be noticed that the owners' and sponsors' perspective describes general jobs and wishes from a business or functional manager, who is interested in achieving their tasks. This fact is reasonable since roadmapping as a service is intended to support managers' activities and jobs, which could indeed be delivered through the application of other management approaches and methods. However, when it comes to pains and gains, a slight convergence with roadmapping characteristics is found, such as 'difficulty of protecting sensitive information', 'difficulty of involving external people', 'application of agile process and practices', and 'support for participants reaching agreements'. This fact shows to some extent that roadmapping, differing to other approaches, can cover multiple factors related to managers' jobs. It is not the purpose of this paper to compare the contribution of roadmapping to other management approaches, such as Delphi Method or Scenario Planning, but it could be interesting to investigate how the alternative approaches are capable of supporting managers' jobs.

In addition, jobs identified from the owners' and sponsors' perspective are aligned with common goals and objectives of roadmapping processes (Phaal et al., 2004). This point confirms that roadmapping use is in accordance with jobs required and, thus, can satisfy roadmapping owners and sponsors. Nevertheless, for this same perspective, when roadmapping literature is analysed in terms of the pains and gains described, it seems that new actions could be taken to support roadmapping improvements. For example, there is little literature on how to deal with pains like 'difficulty of defining scope of analysis' and 'difficulty of protecting sensitive information'. Similarly, gains like 'support for participants reaching agreement' and 'support for the sharing of expert knowledge' could be further explored by research.

In Table 2, the team members' perspective shows factors which are to some extent aligned with workshop approaches. The thematic line of knowledge building and sharing, which can be noted in all parts of the model, appears to be the only one with more specific alignment to roadmapping (e.g.: 'sharing and acquisition of knowledge and insights', 'fear of sharing ideas and loss of ownership', and 'lack of expertise in the scope of analysis'). There are three other lines that can be pointed out, although potentially related to any workshop-based activities: group working, decision making, social 
interactions, information and data. The team members' perspective can be considered underexplored in roadmapping literature. Although it is clearly relevant for the quality and success of roadmapping efforts, little is known of how to enhance team members contribution. Initial guidance can be reached through studies that addressed roadmapping team members indirectly (Gerdsri et al., 2009; 2010; Kerr et al., 2012a).

In Table 2, the facilitators' perspective presents more information and, thus, it seems to be the richest perspective. This fact could be caused by the experts' experience as roadmapping facilitators. However, since this result is intended to be further refined with other participants, existent biases will be controlled and reduced in the future. For this perspective, although there are general factors applicable to other management approaches, there are many factors that address characteristics particularly related to roadmapping. For example: 'promotion of a creative and learning-oriented environment', 'difficulty of following the designed roadmapping process', ' difficult and timeconsuming data processing', 'workload uncertainty', 'misaligned expectations about the roadmapping results', and 'presence of rich and multidisciplinary debates'.

Although the facilitators' perspective is directly benefited by the knowledge available in literature, which helps with conducting effective roadmapping, there is also interest in improving roadmapping efficiency. At this point, for example, the introduction of digital technologies for data acquisition, sharing and management could help with 'Management and Sharing of Data and Information' and 'Difficult and time-consuming data processing'. In addition, digital technologies for collaboration among participants could help with 'limited participation and interaction' and 'Roadmapping Results Agreed Among Participants'.

\section{FINAL CONSIDERATIONS}

This paper describes results of an ongoing research project. It firstly set the importance of carefully considering the transition from traditional roadmapping (mostly conducted through manual and faceto-face practices) to digital roadmapping (conducted with support of digital technologies). Then, it proposes the adoption of the service lens to roadmapping, i.e. start dealing with roadmapping as a service that is offered to solve customer needs.

Using the concept of roadmapping service, the paper applies the theory of customer jobs to investigate and analyse jobs, pains, and gains related to roadmapping. Three customer perspectives were covered in this study: owners and sponsors, team members, and facilitators. This is the first step in the transition to digital roadmapping, since it supports understanding and designing the digital roadmapping value.

Based on a literature review and interviews with experts, data was collected, and the customer perspectives of roadmapping were defined and analysed. The results show that roadmapping supports several traditional jobs required by business and functional managers, mainly in terms of the owners' and sponsors' perspective. Although other management approaches could be used to support these jobs, it seems that roadmapping is related to specific gains and pains, which require further understanding before moving to the digitalisation of roadmapping.

This paper contributes mainly by providing a new lens for analysing and improving roadmapping processes. Looking at roadmapping from different customer perspectives shows that there is still space for improving the value offer of roadmapping, in particular when addressing facilitators' and team members' perspectives, which seem to have been little explored in the existent literature.

The understanding of roadmapping as a service - the concept of Roadmapping Service - can be considered a theoretical contribution as it consolidates views from other research domains and gives the opportunity to improve the existing knowledge surrounding roadmapping. From the empirical side, the description of roadmapping jobs, pains, and gains for the three customer perspectives can be used by practitioners to assess their roadmapping processes and seek improvements.

The next steps of this study will involve a further analysis of the three customer perspectives of roadmapping considered. This analysis includes the review and validation of the jobs, pains, and gains, as well as their prioritisation. Following this, a comparison between the perspectives will be carried out to clarify if there are common interests for each customer type, and which are the most important jobs to be addressed for delivering roadmapping as a service. Based on this information, a proposal for digital roadmapping should be designed in a way that pains are reduced, gains maximized, and potential flexibility is included to address the different priorities of specific customers. Finally, this proposal 
should be compared to current roadmapping practices and, thus, advantages and disadvantages of digitalisation will be discussed.

\section{REFERENCES}

Bettencourt, L.A., Lusch, R.F. and Vargo, S.L. (2014), “A service lens on value creation: Marketing's role in achieving strategic advantage”, California Management Review, Vol. 57 No. 1, pp. 44-66.

Blessing, L.T.M. and Chakrabarti, A. (2009), DRM - A Design Research Methodology, Springer-Verlag, Heidelberg.

Bloomberg, J. (2018), "Digitization, digitalization, and digital transformation: Confuse them at your peril", Forbes, available at: https://www.forbes.com/sites/jasonbloomberg/2018/04/29/digitization-digitalizationand-digital-transformation-confuse-them-at-your-peril/\#6e1329a62f2c (accessed 10 October 2018).

Bray, O.H. and Garcia, M.L. (1997), "Technology roadmapping: the integration of strategic and technology planning for competitiveness", In: Innovation in Technology Management - The Key to Global Leadership. PICMET '97: Portland International Conference on Management and Technology, pp. 25-28.

Brown, T. (2009), Change by design: how design thinking transforms organizations and inspires innovation, Harper Business, New York.

Carvalho, M.M., Fleury, A. and Lopes, A.P. (2013), “An overview of the literature on technology roadmapping (TRM): Contributions and trends", Technological Forecasting and Social Change, Vol. 80 No. 7 , pp. 1418-1437.

Christensen, C.M., Anthony, S.D., Berstell, G. and Nitterhouse, D. (2007), "Finding the right job for your product”, MIT Sloan Management Review, Vol. 48 No. 3, pp. 38-47.

Conforto, E.C., Rebentisch, E. and Amaral, D.C. (2016), "Learning the art of business improvisation", MIT Sloan Management Review, Vol. 57 No. 3, pp. 4-7.

Cosner, R.R., Hynds, E.J., Fusfeld, A.R., Loweth, C. V., Scouten, C. and Albright, R. (2007), “Integrating roadmapping into technical planning”, Research Technology Management, Vol. 50 No. 6, pp. 31-48.

EIRMA. (1997), Technology Roadmapping: Delivering Business Vision, No. Working Group Report 52, Paris.

Gerdsri, N., Assakul, P. and Vatananan, R.S. (2010), “An activity guideline for technology roadmapping implementation”, Technology Analysis and Strategic Management, Vol. 22 No. 2, pp. 229-242.

Gerdsri, N., Kongthon, A. and Vatananan, R.S. (2013), "Mapping the knowledge evolution and professional network in the field of technology roadmapping: A bibliometric analysis", Technology Analysis and Strategic Management, Vol. 25 No. 4, pp. 403-422.

Gerdsri, N., Vatananan, R.S. and Dansamasatid, S. (2009), "Dealing with the dynamics of technology roadmapping implementation: A case study", Technological Forecasting and Social Change, Elsevier Inc., Vol. 76 No. 1, pp. 50-60.

Groenveld, P. (1997), "Roadmapping integrates business and technology", Research-Technology Management, Routledge, Vol. 40 No. 5, pp. 48-55.

Grossman, D.S. (2004), "Putting technology on the road", Research-Technology Management, Routledge, Vol. 47 No. 2, pp. 41-46.

Hess, T., Benlian, A., Matt, C. and Wiesböck, F. (2016), "Options for formulating a digital transformation strategy”, MIS Quarterly Executive, Vol. 15 No. 2, pp. 123-139.

Hill, G.M. (2004), "Evolving the project management office: A competency continuum”, Information Systems Management, Vol. 21 No. 4, pp. 45-51.

Hill, T.P. (1977), “On goods and services”, Review of Income and Wealth, Vol. 23 No. 4, pp. 315-338.

Kappel, T.A. (2001), "Perspectives on roadmaps: How organizations talk about the future", Journal of Product Innovation Management.

Karlsson, C. (2016), Research Methods for Operations Management, 2nd ed., Taylor \& Francis, London.

Kerr, C. and Phaal, R. (2015), "Visualizing roadmaps: A design-driven approach", Research-Technology Management, Vol. 58 No. 4, pp. 45-54.

Kerr, C., Phaal, R. and Probert, D. (2012a), "Cogitate, articulate, communicate: the psychosocial reality of technology roadmapping and roadmaps", $R \& D$ Management, Vol. 42 No. 1, pp. 1-13.

Kerr, C.I.V., Phaal, R. and Probert, D.R. (2012b), "Addressing the cognitive and social influence inhibitors during the ideation stages of technology roadmapping workshops", International Journal of Innovation and Technology Management, Vol. 9 No. 6, p. 1250046.1-1250046.20.

Kostoff, R.N. and Schaller, R.R.R.R. (2001), "Science and technology roadmaps", IEEE Transactions on Engineering Management, Vol. 48 No. 2, pp. 132-143.

Lanzolla, G. and Anderson, J. (2008), "Digital transformation”, Business Strategy Review, Vol. 19 No. 2 , pp. 72-76.

Liker, J.K. (2004), The Toyota Way, McGraw-Hill, New York.

McAfee, A. and Brynjolfsson, E. (2017), Machine, Platform, Crowd: Harnessing Our Digital Future, W.W. Norton \& Company, New York.

McIntosh, C. (2013), Cambridge Advanced Learner's Dictionary, Cambridge University Press. 
Oliveira, M.G., Freitas, J.S., Fleury, A.L., Rozenfeld, H., Phaal, R., Probert, D. and Cheng, L.C. (2012), Roadmapping: Uma Abordagem Estratégica Para o Gerenciamento Da Inovação Em Produtos, Serviços e Tecnologias, Elsevier, Rio de Janeiro.

Osterwalder, A. and Pigneur, Y. (2010), Business model generation: a handbook for visionaries, game changers, and challengers, John Wiley \& Sons, Hoboken, N.J.

Osterwalder, A., Pigneur, Y., Bernarda, G. and Smith, A. (2014), Value Proposition Design, John Wiley \& Sons, New Jersey.

Phaal, R., Farrukh, C., Mitchell, R. and Probert, D. (2003), “Starting-up roadmapping fast”, Research Technology Management, Vol. 46 No. 2, pp. 52-59.

Phaal, R., Farrukh, C. and Probert, D. (2010), Roadmapping for Strategy and Innovation: Aligning Technology and Markets in a Dynamic World, University of Cambridge, Institute for Manufacturing, Cambridge.

Phaal, R., Farrukh, C. and Probert, D. (2006a), "Technology management tools: Concept, development and application", Technovation, Vol. 26 No. 3, pp. 336-344.

Phaal, R., Farrukh, C. and Probert, D. (2006b), "Technology management tools: Generalization, integration and configuration", International Journal of Innovation and Technology Management, Vol. 03 No. 3, pp. 321-339.

Phaal, R., Farrukh, C.J.P. and Probert, D.R. (2001), T-Plan: Technology Road Mapping: Planning Your Route to Success., University of Cambridge, Institute for Manufacturing, Cambridge.

Phaal, R., Farrukh, C.J.P. and Probert, D.R. (2004), "Technology roadmapping - A planning framework for evolution and revolution", Technological Forecasting and Social Change, Vol. 71 No. 1-2, pp. 5-26.

Phaal, R., Farrukh, C.J.P. and Probert, D.R. (2007), "Strategic roadmapping: A workshop-based approach for identifying and exploring strategic issues and opportunities”, Engineering Management Journal, Vol. 19 No. 1, pp. 3-12.

Phaal, R., Kerr, C., Ilevbare, I., Farrukh, C.J.P., Routley, M. and Athanassopolou, N. (2015), "Self-facilitating templates for technology and innovation strategy workshops", R\&D Management Conference, Vol. 2015 No. June, pp. 23-26.

Radnor, M. and Peterson, J.W. (1999), “Aligning strategy and technology using roadmaps: emerging lessons from the NCMS 'MATI' project”, In: PICMET '99: Portland International Conference on Management of Engineering and Technology. Proceedings, CMET, available at: https://dx.doi/org/10.1109/PICMET.1999.807700.

Schimpf, S. and Abele, T. (2017), "How german companies apply roadmapping: Evidence from an empirical study", Journal of Engineering and Technology Management - JET-M, Elsevier, No. October 2016, pp. $1-15$.

Vatananan, R.S. and Gerdsri, N. (2012), “The current state of technology roadmapping (TRM): Research and practice", International Journal of Innovation and Technology Management, Vol. 09 No. 04, p. 1250032.

Vuorinen, T., Hakala, H., Kohtamäki, M. and Uusitalo, K. (2018), "Mapping the landscape of strategy tools: A review on strategy tools published in leading journals within the past 25 years", Long Range Planning, Vol. 51 No. 4, pp. 586-605.

Whitney, D.E. (2007), “Assemble a technology development toolkit”, Research Technology Management, Vol. 50 No. 5, pp. 52-58.

Willyard, H. and McClees, C.W. (1987), "Motorola's technology roadmap process", Research Management, Vol. 30 No. 5, pp. 13-19. 